\title{
Characterisation of a secretory serine protease inhibitor (SjB6) from Schistosoma japonicum
}

\author{
Adebayo J Molehin ${ }^{1,2^{*}}$, Geoffrey N Gobert ${ }^{1}$, Patrick Driguez ${ }^{1}$ and Donald P McManus ${ }^{1}$
}

\begin{abstract}
Background: Proteins belonging to the serine protease inhibitor (serpin) superfamily play essential physiological roles in many organisms. In pathogens, serpins are thought to have evolved specifically to limit host immune responses by interfering with the host immune-stimulatory signals. Serpins are less well characterised in parasitic helminths, although some are thought to be involved in mechanisms associated with host immune modulation. In this study, we cloned and partially characterised a secretory serpin from Schistosoma japonicum termed SjB6, these findings provide the basis for possible functional roles.

Methods: SjB6 gene was identified through database mining of our previously published microarray data, cloned and detailed sequence and structural analysis and comparative modelling carried out using various bioinformatics and proteomics tools. Gene transcriptional profiling was determined by real-time PCR and the expression of native protein determined by immunoblotting. An immunological profile of the recombinant protein produced in insect cells was determined by ELISA.
\end{abstract}

Results: SjB6 contains an open reading frame of 1160 base pairs that encodes a protein of 387 amino acid residues. Detailed sequence analysis, comparative modelling and structural-based alignment revealed that SjB6 contains the essential structural motifs and consensus secondary structures typical of inhibitory serpins. The presence of an $\mathrm{N}$-terminal signal sequence indicated that SjB6 is a secretory protein. Real-time data indicated that SjB6 is expressed exclusively in the intra-mammalian stage of the parasite life cycle with its highest expression levels in the egg stage $(p<0.0001)$. The native protein is approximately $60 \mathrm{kDa}$ in size and recombinant SjB6 (rSjB6) was recognised strongly by sera from rats experimentally infected with $S$. japonicum.

Conclusions: The significantly high expression of SjB6 in schistosome eggs, when compared to other life cycle stages, suggests a possible association with disease pathology, while the strong reactivity of sera from experimentally infected rats against $r \mathrm{SjB} 6$ suggests that native SjB6 is released into host tissue and induces an immune response. This study presents a comprehensive demonstration of sequence and structural-based analysis of a secretory serpin from a trematode and suggests SjB6 may be associated with important functional roles in S. japonicum, particularly in parasite modulation of the host microenvironment.

Keywords: Schistosoma japonicum, Serpin, SjB6, Host-parasite interaction, Structural analysis

\footnotetext{
* Correspondence: adebayo.molehin@qimrberghofer.edu.au

${ }^{1}$ Molecular Parasitology Laboratory, QIMR Berghofer Medical Research Institute, 300 Herston Road, Herston 4006, Australia

${ }^{2}$ School of Population Health, The University of Queensland, 300 Herston

Road, Herston, Brisbane 4006, Australia
} 


\section{Background}

Serine protease inhibitors (serpins) are members of an important superfamily of structurally-related proteins found in many organisms including viruses, bacteria, animals and plants [1-4]. Serpins participate in many important physiological processes such as signalling cascades [5], blood coagulation [6,7], fibrinolysis [8], inflammation and activation of the complement system $[9,10]$. Furthermore, these inhibitors also play key roles in host immune modulation by pathogens, and hence the suggestion that pathogen serpins may have evolved for the singular purpose of limiting host immune activation by interfering with host immunomodulatory signals $[11,12]$. In parasitic helminths, these inhibitors appear to perform similar roles [13].

Schistosoma japonicum is a zoonotic trematode that infects humans and many animals causing Asiatic schistosomiasis. Despite considerable control measures, high re-infection rates and the potential for the development of drug resistance, necessitate the development of an effective anti-schistosomal vaccine, which would significantly decrease the schistosomiasis-induced morbidity and mortality in endemic areas. Despite significant research regarding the biology and immunology of schistosomiasis, much is still unknown regarding the mechanisms associated with schistosomes evading the host immune responses or the involvement of serpins in these processes. In particular, there are limited reports to date presenting the functional characterisation of serpins in the Asiatic schistosomes or their possible role in host-parasite interactions.

Through the analysis of the transcriptional changes occurring during the S. japonicum life cycle [14] and crossreferencing with the S. japonicum genome database [15], we are able to report here the identification and cloning of a full-length cDNA sequence, termed SjB6 [GenBank: CAX69453.1] encoding a secretory $S$. japonicum serpin. According to MEROPS classification of protease inhibitors [16], SjB6 (MEROPS Accession: ME179730) is a member of inhibitor family 14 (Clan ID). We also present structure-to-function bioinformatics analysis of the SjB6 polypeptide, its production as a recombinant protein and its characterisation.

\section{Methods}

\section{Ethics statement}

All work was conducted with the approval of the QIMR Berghofer Medical Research Institute Animal Ethics Committee (Project number P288).

\section{Identification of S. japonicum serpin}

Source sequence encoding S. japonicum SjB6 [GenBank: CAX69453.1] was found using BLAST (Basic Local Alignment and Search Tool) [17] with the BLASTP and BLASTN algorithms against $S$. japonicum Gene Index (SjGI) available at DFCI (http://compbio.dfci.harvard.edu/tgi/) and a
S. japonicum gene expression database created by our research group [14]. Validation of sequence accuracy was carried out by inspecting and confirming the presence of start and stop codons, the expected amino acid length range for serpins (350-450 amino acids of translated protein sequence) $[1,18]$, and the presence of two amino acids motifs described as highly conserved for serpins: NAVYFKG and DVNEEG [19,20].

\section{Bioinformatics analyses}

The SjB6 coding sequence was compared to known entries in GenBank using the BLASTp program. To gain insight on probable functionality, the deduced SjB6 amino acid sequence was scanned against amino acid motif entries, ScanProsite, THMMM, PROSITE and SignalP servers (ExPASY Bioinformatics Resource Server; http://www. expasy.org/proteomics). The reactive centre loop (RCL) of SjB6 was determined based on the consensus 20/21 residue peptide "p17 [E]-p16 [E/K/R]-p15 [G]-p14 [T/S]-p13 [X]-P12-9 [AGS]-p8-1 [X]-p1' - 4"' [4,21]. The putative scissile bond $(\mathrm{P} 1-\mathrm{P} 1$ ') and the $\mathrm{P} 1$ residue were predicted based on the conserved features that there are generally 17 amino residues (P17 to P1) between the start of the hinge region of the RCL and the scissile bond [1]. Sequence alignment was performed using the MUSCLE algorithm [22,23] in the MEGA 6.0 program [24]. Putative $\mathrm{N}$-glycosylation sites were identified using the NetNGly1.0 server (Gupta et al., unpublished, http://cbs.dtu.dk/services/ NetNGlyc/). Theoretical molecular weight and isoelectric points of the mature serpin protein were calculated using the ExPASy Compute pI/Mw tool [25].

\section{Structural based sequence alignment and comparative modelling}

The SjB6 amino acid sequence was subjected to structural based alignment using STRAP [26] and the MUSCLE algorithm [22]. The tertiary structures of SjB6 and other parasitic helminth serpins were predicted using the Phyre ${ }^{2}$ program [27]. QMEAN was the method used to estimate model reliability and predict quality $[28,29]$. The predicted structures were aligned and viewed using DeepViewSWISS PdbViewer v4.1 [30]. Illustrations of the 3D structures were generated using DeepView-SWISS PdbViewer.

\section{Phylogenetic analysis}

Multiple amino acid sequence alignments of SjB6 and some other parasite serpins retrieved from GenBank (GenBank accession numbers in Table 1) were created using the MUSCLE algorithm [22] in an open source Phylogeny.fr program [31]. The phylogenetic analyses were performed using default setting of the "One Click mode" in Phylogeny.fr program [31] with Gblocks for automatic curation [32], PhyML for tree building [33] and TreeDyn for tree drawing [34]. 
Table 1 Key characteristics of the serpin SjB6 sequence

\begin{tabular}{lll}
\hline & Amino acid sequence & $\begin{array}{l}\text { Amino acid } \\
\text { position }\end{array}$ \\
\hline Serpin motif & DEEGAV & $329-334$ \\
Reactive Central Loop & AASASATVMYMCSAIRSHQPVPE & $337-357$ \\
Serpin signature & FRIDHPFFISI & $358-368$ \\
\hline
\end{tabular}

\section{Parasite materials}

A Chinese field isolate (Anhui strain) of S. japonicum was maintained in Oncomelania hupensis hupensis snails and in BALB/c mice (Animal Resource Centre, Western Australia) at QIMR Berghofer Medical Research Institute. Adult worms were recovered by perfusion of infected mice using sodium citrate buffer ( $0.15 \mathrm{M}$ sodium chloride/ $0.05 \mathrm{M}$ sodium citrate). Soluble worm antigen products (SWAP) were obtained from homogenised adult worm pairs following centrifugation. Eggs were obtained from infected mouse livers and miracidia hatched from isolated eggs as described [35]. The production of cercariae [36] and schistosomula, obtained by mechanical transformation of cercariae [37], followed published procedures. All parasite stages were stored in liquid nitrogen until needed or stored in RNAlater (Ambion) at $4^{\circ} \mathrm{C}$ until total RNA extraction.

\section{Total RNA extraction, CDNA synthesis and real-time PCR}

Total RNA was extracted from isolated S. japonicum life cycle stages using Trizol reagent (Life Technologies) and an RNeasy Mini kit (Qiagen). Total RNA quantity was measured using Nanodrop-1000 (Nanodrop Technologies) and quality assessed using an Agilent Bioanalyzer (Agilent Technologies). cDNA was synthesised from total RNA obtained using a Quantitect Reverse Transcription Kit (Qiagen) according to the manufacturer's instructions. Real-time PCR for SjB6 was performed using $2.5 \mathrm{ng}$ of cDNAs as templates with the SYBR Green PCR Master Mix (Applied Biosystems). Primers were designed from cDNA sequences using Primer3 (http://primer3.wi.mit. edu/). The forward primer was 5'- TTG ACC AGT TTA CCA CAC CTA CA- 3' and the reverse primer was 5'AGA CAG CAA TGA AGA GAT TCC AC - 3'. NADHubiquinone reductase (NADH-UR) was used as housekeeping gene [14]. The cycling conditions were: $95^{\circ} \mathrm{C}$ for $10 \mathrm{~min} ; 39$ cycles at $95^{\circ} \mathrm{C}$ for $30 \mathrm{~s}$ at $58^{\circ} \mathrm{C}$ for $30 \mathrm{~s}$ and $72^{\circ} \mathrm{C}$ for $30 \mathrm{~s}$. All reactions were carried out in four biological replicates. Rotor-Gene 6000 series software and GraphPad Prism software were used to analyse the results.

\section{Cloning of the SjB6 gene and sequence analysis}

The full-length coding sequence of SjB6 was amplified from adult worm cDNA by PCR using oligonucleotide primers flanking the open reading frame of the gene designed using Amplify 3 (http://engels.genetics.wisc.edu/ amplify/). The forward primer was 5'- CGT ATA CAT TTC TTA CAT CTA TGC GGA TTC GCA TCA CCA TCA CCA TCA CGT TCT TTG CGG TAG TGA TAA TAA TAC GAA AGC T-3' and the reverse primer was 5'- GTT AGT GGT GGT GGT GGT GGT GTT ATT CAT TCA TTG GTG CTA CAA CAT GTC CTA GA-3'. The amplification reaction was carried out using a thermal cycling profile of $95^{\circ} \mathrm{C}$ for $2 \mathrm{~min} ; 30$ cycles at $95^{\circ} \mathrm{C}$ for $20 \mathrm{~s}, 60^{\circ} \mathrm{C}$ for $20 \mathrm{~s}, 70^{\circ} \mathrm{C}$ for $20 \mathrm{~s}$ and a final extension for $2 \mathrm{~min}$ at $72^{\circ} \mathrm{C}$. The PCR product was analysed on a $0.8 \%$ $(\mathrm{w} / \mathrm{v})$ agarose gel, gel-purified and co-transformed with linearised p-BAC-1 transfer vector into Escherichia coli OmniMAX competent cells (Invitrogen). Positive clones were screened for the presence of plasmid with the appropriate insert. The nucleotide sequence of the insert was determined by automated sequencing.

\section{Generation of recombinant pBAC-1/SjB6 plasmid DNA}

Standard insect cell culture techniques were used as previously described [38,39]. Sf9 cells seeded at $6 \times 10^{5}$ cells/mL in Sf900II medium were plated into a 24-deep well plate (Invitrogen) and transfected with a mixture of 100 ng recombinant $\mathrm{pBAC}-1 / \mathrm{SjB} 6$ plasmid DNA and 20 ng flashBAC DNA [40] using Cellfectin (Invitrogen) according to the manufacturer's instructions. Cells were then incubated at $28^{\circ} \mathrm{C}$ for $5 \mathrm{hr}$ and the supernatant removed afterwards. Media supplemented with Gibco antibiotics-antimycotics (100X) solution (Life Technologies) was added and the cells incubated at $28^{\circ} \mathrm{C}$ for a further 7 days. Cells were pelleted $(500 \times g, 5 \mathrm{mins})$ and the supernatant containing P1 virus was stored at $4^{\circ} \mathrm{C}$ until needed. Cell growth, average cell size and viability were monitored using Countess Automated Cell Counter (Life Technologies).

\section{Virus amplification and expression of $\mathrm{rSjB} 6$}

Sf9 cells seeded at $2 \times 10^{6}$ cells $/ \mathrm{ml}$ were infected with $\mathrm{P} 1$ virus and incubated at $28^{\circ} \mathrm{C}$ at $250 \mathrm{rpm}$ for 4 days in a humidified incubator. At $96 \mathrm{~h}$ post-infection, the cells were pelleted and the supernatant containing $\mathrm{P} 2$ virus was harvested and stored at $4^{\circ} \mathrm{C}$. For the expression of rSjB6, High-Five (Hi-5) cell culture seeded at $1.5 \times 10^{6}$ cells/ml was infected with the P3 virus and incubated at $28^{\circ} \mathrm{C}$ at $120 \mathrm{rpm}$ for $48 \mathrm{~h}$ in a humidified incubator. At $48 \mathrm{~h}$ post-infection, the supernatant was collected by centrifugation, filtered through $0.45 \mu \mathrm{m}$ filter and affinity purified.

\section{Affinity purification followed by size exclusion chromatography}

The filtered supernatant was loaded into prepacked $1 \mathrm{ml}$ HisTrap excel IMAC column (GE Healthcare). The column was washed with wash buffer $(20 \mathrm{mM}$ Sodium phosphate, $500 \mathrm{mM} \mathrm{NaCl}, 20 \mathrm{mM}$ Imidazole, $\mathrm{pH}$ 7.1) before a 
multi-step elution, whereby increasing concentrations $(4 \%, 8 \%, 16 \%, 26 \%, 50 \%$ and $100 \%)$ of elution buffer (20 mM Sodium phosphate, $500 \mathrm{mM} \mathrm{NaCl}, 500 \mathrm{mM}$ Imidazole) were used to elute the protein of interest (Figure 1). Each concentration was held until a baseline absorbance was reached. Purification steps were performed on AKTA Explorer FPLC system (GE Healthcare) at a flow rate of $1 \mathrm{~mL} / \mathrm{min}$ at $4^{\circ} \mathrm{C}$. Eluted protein fractions were dialysed against phosphate buffered saline $(\mathrm{pH}$ 7.4) and loaded into a S75 SEC column with AKTA Explorer FPLC system at $0.5 \mathrm{~mL} / \mathrm{min}$, at $4^{\circ} \mathrm{C}$. Protein fractions collected were analysed on SDS PAGE and the yield determined by standard Bradford assay [41]. The recombinant protein was stored at $-20^{\circ} \mathrm{C}$ until needed.

\section{Assay of native SjB6 protein in S. japonicum}

Production of rabbit antiserum was carried out by Antibody Production Services (South Australian Health and Medical Research Institute, Australia). Briefly, the rabbit was immunised 3 times with $250 \mu \mathrm{g} \mathrm{rSjB6}$ at 3-week intervals.
The polyclonal antiserum was collected 7 days after the last immunisation and stored at $-80^{\circ} \mathrm{C}$ until required. Western blotting was performed according to the LI-COR Biosciences protocol. Briefly, rSjB6 and SWAP of S. japonicum and subjected to electrophoresis on a $4-12 \%(\mathrm{w} / \mathrm{v})$ NuPAGE gel (Invitrogen). After separation, electrophoretic transfer of proteins from the polyacrylamide gel to Immuno-Blot LF PVDF (Bio-Rad) membrane was achieved using a XCell II Blot Module (Invitrogen) at $25 \mathrm{~V}$ for $2 \mathrm{~h}$. Membranes were blocked with Odyssey Blocking buffer (OBT, LI-COR Biosciences) overnight at $4^{\circ} \mathrm{C}$, then incubated with the primary antibodies (antirSjB6 antiserum and normal rabbit serum as control) for $1 \mathrm{~h}$ at room temperature (1:1000 dilution of rabbit antiserum in $0.2 \%(\mathrm{v} / \mathrm{v})$ Tween-20 in OBT). The membranes were washed with PBST (PBS with $0.1 \%(\mathrm{v} / \mathrm{v})$ Tween-20) and then incubated with secondary antibody (IRDyelabeled goat anti-rabbit IgG $(\mathrm{H}+\mathrm{L})$ at 1:20,000 dilution, LICOR Biosciences) in $0.02 \%(w / v)$ SDS in OBT for $1 \mathrm{~h}$ at room temperature. After further washes with PBST,

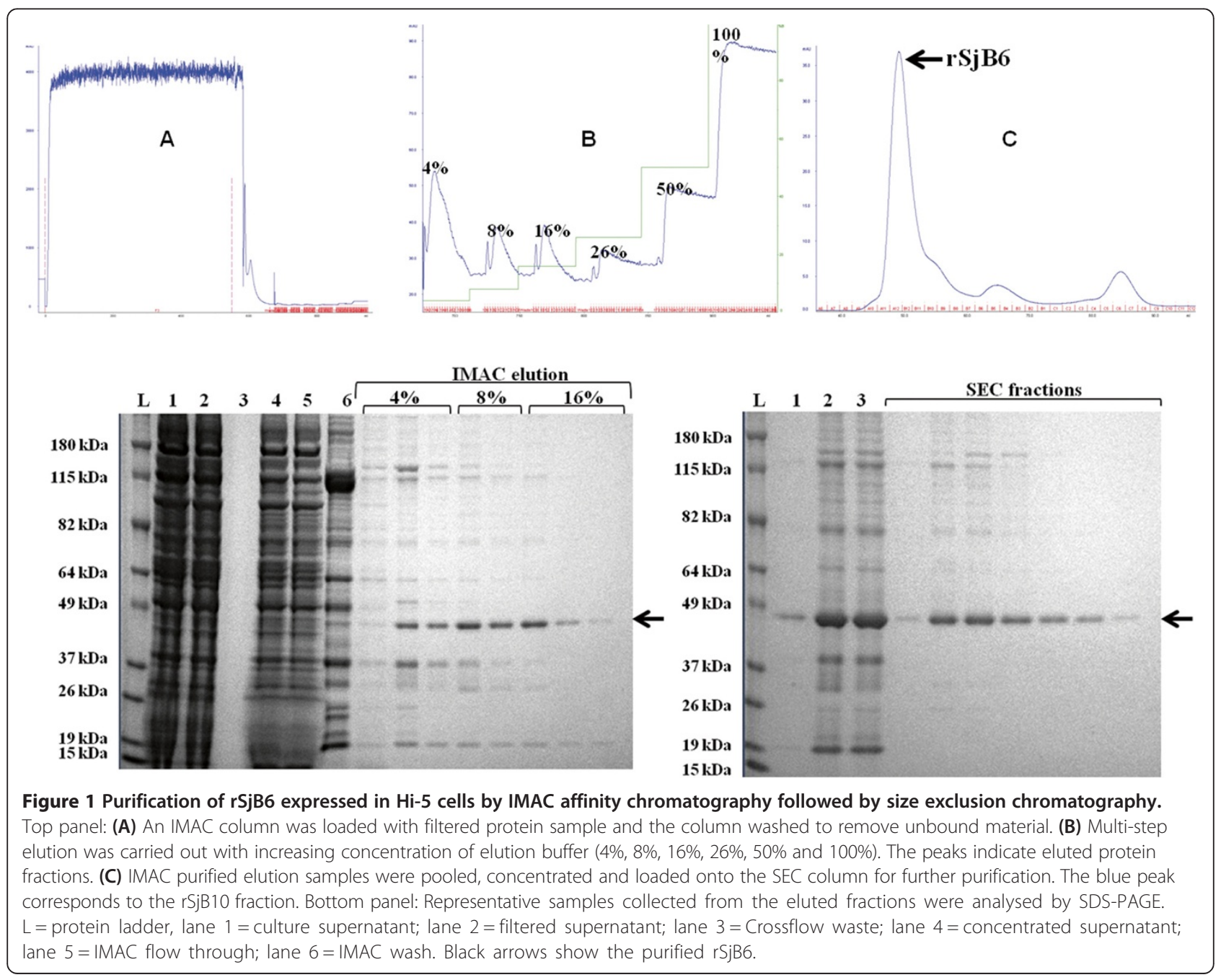


the immunoreactions were visualised with a LICOR Odyssey Infrared Imager.

Experimental challenge infection of rodents, measurement of serum anti-SjB6 antibodies

The laboratory rat is a resistant host for experimental infections with $S$. japonicum while the mouse is a susceptible host [42-44]. Two infection time-course experiments were completed with outbred Wistar rats (7 weeks old) and Swiss outbred mice $(8-12$ weeks old) (Animal Resource Centre, Australia). Rats $(\mathrm{N}=3)$ and mice $(\mathrm{N}=5)$ were infected percutaneously with 200 and 60 S. japonicum cercariae, respectively, using the cover slip method. Blood samples were collected from mice prior to infection and 6 weeks post-challenge while in the rat time-course experiment, blood samples were collected after a primary and a secondary cercarial challenge (as above) based on the observation that immune resistance in rats re-challenged with schistosomes was shown to be highest between 4-8 weeks after re-infection $[45,46]$. Blood was collected via the tail vein (rats), the tail tip (mice) or from cardiac puncture at necropsy. Sera were obtained from clotted blood by centrifugation and stored at $-80^{\circ} \mathrm{C}$ until required.

The levels of anti-SjB6 antibodies in the sera of individual mice and rat were determined by standard ELISA. Briefly, microplates were coated with $0.5 \mu \mathrm{g} / \mathrm{mL}$ of $\mathrm{rSjB} 6$. Plates were washed with PBST and blocked with $5 \%$ $(\mathrm{w} / \mathrm{v})$ skim milk in PBST. After washing, plates were incubated with mouse sera in blocking buffer for a further $1.5 \mathrm{~h}$ at $37^{\circ} \mathrm{C}$ before being incubated with second antibody (goat anti-mouse IgG conjugated to HRP, Sigma Aldrich) and subsequently developed with substrate solution (SIGMAFast OPD tablets). The endpoint antibody titre was defined as the dilution with an OD reading 2 times above the background level. The protocol for ELISA using the rat sera was identical to that of the mouse except for the secondary antibody used (goat anti-rat IgG conjugated to biotin, Sigma Aldrich) and an additional incubation with HRP conjugated to streptavidin (BD Biosciences) before developing with the substrate solution. Soluble worm antigen products were used as positive control antigen.

\section{Statistical analysis}

Data were expressed as mean \pm standard error of mean (SEM). Changes in real time PCR data and immunological parameters were assessed by One-way ANOVA with post hoc Bonferroni testing ( $\mathrm{p} \leq 0.05)$. These analyses were performed using the GraphPad Prism version 6.02 (GraphPad Software).

\section{Results}

Cloning and general characteristics of SjB6

The cloned full-length cDNA of SjB6 (1160 nucleotides) contained a complete open reading frame (ORF) encoding a polypeptide of 387 amino acids with a predicted molecular weight of $43.7 \mathrm{kDa}$ and a pI of 6.19. Analysis of the deduced $\mathrm{SjB} 6$ peptide indicated the presence of three conserved motifs, namely a serpin motif, a serpin signature and a RCL (Table 1), located near the $\mathrm{C}$-terminal with the cleavage site of the RCL at position 346C-S347. Three N-glycosylation sites (9NFTD12,

\section{MAALQSLTNFTDKFYEQMLKEIHGHWINTFLSPFNIYTAIAMVLCGSDNNTKA

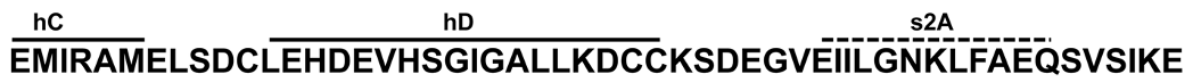 hE s1A RFKNDLKRYYDASAVNMPFQLDPKGSRMQINQWVSEQTKGKIQELLSPDSI TQDTSVIVTATTYFKGMWKLPFPEYNSHVSEFHKLDGSNINVKLMFNEANFN LTSLPHLQSRAIKIPFKNPKFTLLVVLPDANNGLPDLLKLMYKKGGIFSLLFN

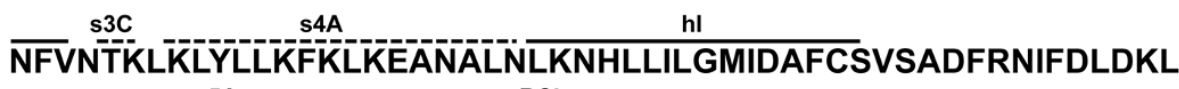 FISDVMHKVIFEV
W5EGAVAAAASATVMLKCSAIRSHQPVPEFRIDHPFFISIII
$\frac{\begin{array}{c}\text { Serpin } \\ \text { signature }\end{array}}{\text { WNDCLPLFLGHVAPMNE }}$}

Figure 3 Predicted amino acid sequence of SjB6 showing the position of conserved alpha helices and beta strands. Secondary structures were assigned based on the 1HP7 tertiary structure; bold lines are a-helices and broken lines are $\beta$-strands. Helices are labelled from "hA" to "hl" and $\beta$-strands that constitute $\beta$-sheet A-C are labelled as "sA", "sB" and "sC" respectively. The highly and lowly conserved residues are labelled in black and grey, respectively. Sequences highlighted in red are $\mathrm{N}$-glycosylation sites. Sequences in the box represent the RCL while double bold lines represent the serpin signature. 


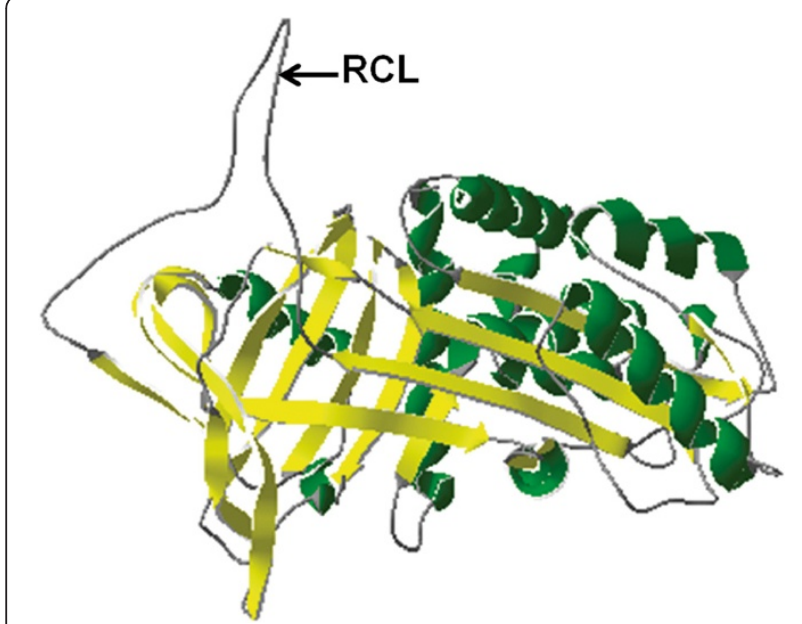

Figure 4 Predicted tertiary structure of SjB6. The figure shows the protein in its native conformation with the RCL (indicated by black arrow) being surface accessible by target protease. The green colour represents the a-helices, the yellow colour represents the $\beta$-sheets, while loops are coloured grey.

49NTKA52 and 209NLTS212) and one glycosaminoglycan attachment site (72SGIG75) were identified on the polypeptide. The $\mathrm{SjB} 6$ polypeptide contained two protein kinase $\mathrm{C}$ phosphorylation sites, one tyrosine phosphorylation site and microbodies C-terminal targeting signal. A signal peptide was found at the $\mathrm{N}$-terminal of the polypeptide but no transmembrane domain was found indicating that $\mathrm{SjB} 6$ was a secretory serpin. Analysis of the SjB6 RCL showed that the hinge region contained the consensus sequence typical of the RCL hinge region, a characteristic common to all inhibitory serpins " $\mathrm{P}_{17}[\mathrm{E}]-\mathrm{P}_{16}[\mathrm{E} / \mathrm{K} / \mathrm{R}]-\mathrm{P}_{15}[\mathrm{G}]-\mathrm{P}_{14}[\mathrm{~T} / \mathrm{S}]-\mathrm{P}_{13}[\mathrm{X}]-\mathrm{P}_{12-9}$
[AGS]- $\mathrm{P}_{8-1}[\mathrm{X}]-\mathrm{P}_{1,-4}, "[4,21]$, with residue variation only at position $\mathrm{P}_{14}$.

Multiple sequence alignment of the deduced SjB6 amino acid sequence with key known parasitic helminth serpins from Genbank showed between 21 - 54\% homology (Figure 2) with the highest sequence homology to S. mansoni serpin (Accession number CCD60349.1). SjB6 sequence showed very low overall sequence homology to serpins from other organisms including humans (data not shown). Analysis of the secondary structure using SWISS-MODEL (http://swissmodel.expasy.org/) and Phyre ${ }^{2}$ [27] showed that SjB6 contains nine $\alpha$-helices and thirteen $\beta$-strands (Figure 3).

\section{Structure-based alignment analysis of SjB6}

Alignment of the predicted tertiary structure of SjB6 (Figure 4) with other predicted tertiary structures of helminth serpins showed that $\mathrm{SjB} 6$ is structurally similar, with the greatest similarity to $S$. mansoni serpin (GenBank: CD60349.1) (Table 2). The root mean squared values ranged between 0 and 2 . The root mean squared value indicates the degree of similarity between the threedimensional structures of two proteins by measuring the root-mean-square distance between equivalent atom pairs from both proteins [47].

\section{Phylogenetic analysis}

Phylogenetic analysis of the amino acid sequence of SjB6 with other helminth parasite serpins indicated two major groups - Group A and Group B. The former comprises serpins formed by clusters A, B and C while the latter comprises serpins formed by clusters $\mathrm{D}$. The 4 phylogenetic clusters were supported by the aLRT statistical test [61] showing branch support values of $100 \%$ for clusters A

Table 2 Structural alignment of SjB6 with human a1-antitrypsin and known helminth serpins

\begin{tabular}{|c|c|c|c|c|c|}
\hline Serpin name & Genbank accession number & Source & Reference & RMS value $(\AA)$ & No of atoms involved \\
\hline a1-antitrypsin & AY256958 & Humans & Bollen et al. [48] & 1.30 & 288 \\
\hline SRP-3 & AY525080 & C. elegans & Pak et al. [49] & 1.29 & 235 \\
\hline CSSERPIN & EF550965 & C. sinensis & Kang et al. & 1.15 & 238 \\
\hline Serpin $^{\text {Emu }}$ & CAD12372.2 & E. multilocularis & Merckelbach and Ruppel [50] & 1.15 & 235 \\
\hline Hc-serpin & ACP43576 & H. contortus & Yi et al. [51] & 1.23 & 247 \\
\hline PWSERPIN & EU014295 & P. westermani & Hwang et al. [52] & 1.18 & 239 \\
\hline Sh serpin & AAA19730 & S. haematobium & Blanton et al. [53] & 1.52 & 221 \\
\hline Sj serpin & AAK57435 & S. japonicum & Yan et al. [54] & 1.49 & 216 \\
\hline Smpi56 & CCD60349 & S. mansoni & Ghendler et al. [55] & 1.16 & 240 \\
\hline Contrapsin & CCD60352 & S. mansoni & Modha and Doenhoff [56] & 1.16 & 240 \\
\hline Ts11-1 & DQ864973 & T. spiralis & Nagano et al. [57] & 1.22 & 248 \\
\hline Tv Serp & Y12233 & T. vitrinus & MacLennan et al. [58] & 1.20 & 296 \\
\hline Bm-spn-1 & U04206 & B. malayi & Yenbutr and Scott [59] & 1.14 & 305 \\
\hline Bm-spn-2 & AF009825 & B. malayi & Zang et al. [60] & 1.19 & 298 \\
\hline
\end{tabular}




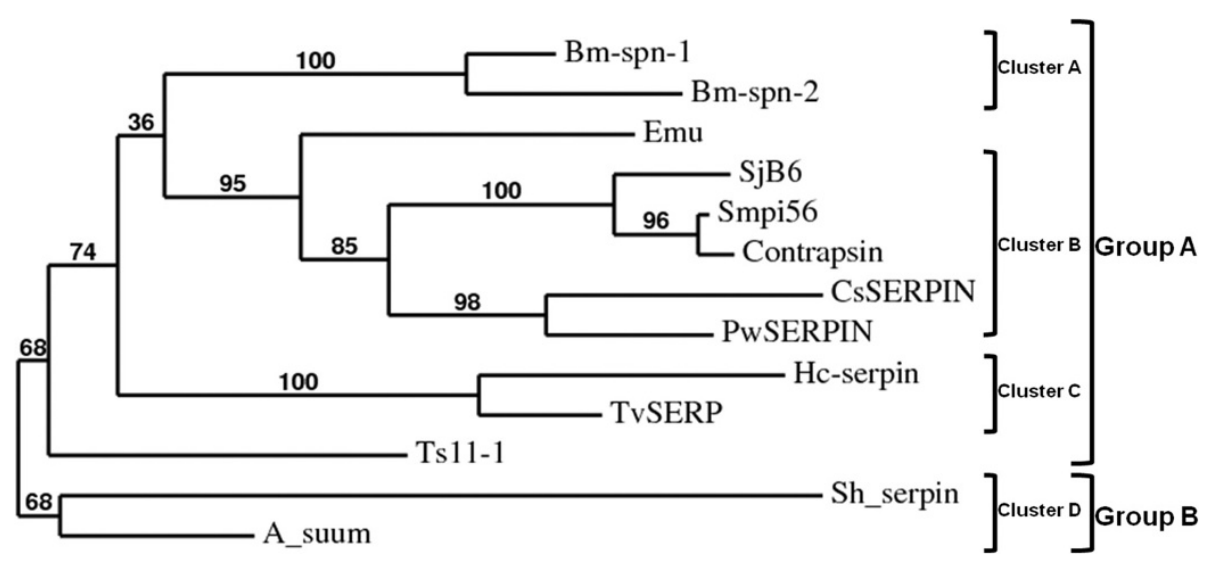

Figure 5 Phylogenetic tree analysis of amino acid sequences for SjB6 and other parasitic helminth serpins. The alignment of retrieved sequences (GenBank accession numbers shown in Table 2) was created using MUSCLE. All sequences were retrieved from GenBank.

and C, $95 \%$ for cluster B and 65\% for cluster D (Figure 5). SjB6 is closely related to Smpi56 and contrapsin grouped within cluster A and sharing 69\% sequence identity.

\section{Gene expression profile of the SjB6 gene}

Stage-specific expression of the SjB6 transcript was examined by real-time PCR using CDNA reverse transcribed from RNA samples isolated from several developmental stages of S. japonicum and primers designed to specifically amplify the SjB6 gene. Expression was detected only in the intra-mammalian stages of the parasite lifecycle with the egg stage showing about 3-fold increase in expression when compared with the other stages and this increase was highly significant $(\mathrm{p} \leq 0.001)$ (Figure 6). The $N A D H$ $U R$ gene used as the internal control showed a constant expression across all the lifecycle stages tested (data not shown).

\section{Expression and purification of recombinant SjB6 in vitro}

The recombinant $\mathrm{SjB} 6$ protein was expressed using the flashBAC baculovirus expression system as a secreted protein. In the first step of purification, IMAC affinity column was used to partially purify $\mathrm{rSjB} 6$. Further purification by size exclusion chromatography resulted in a single protein band of approximately $43 \mathrm{kDa}$ as analysed on a $4-12 \%(w / v)$ NuPAGE gel (Figure 1).

\section{Western blot analysis of native SjB6 in S. japonicum adult worms}

Western blotting was used to determine whether rabbit anti-serum, raised against purified $\mathrm{rSjB} 6$, to was able to react with the native antigen in SWAP. As shown in Figure 7 (lane 3), a highly specific positive signal at an approximate molecular weight of $60 \mathrm{kDa}$ was detected in the SWAP. There was also a positive signal at the expected molecular weight of $43 \mathrm{kDa}$ with the $\mathrm{rSjB} 6$ sample (lane 2, Figure 7), confirming the specificity of the rabbit antiserum. No signal was evident with the SWAP sample incubated with pre-immune rabbit serum (Figure 7, lane 4). The molecular weight of the protein band detected in the SWAP sample probed with rSjB6specific rabbit antiserum was considerably higher than that of rSjB6.

\section{Antibody response of experimentally challenged rodents} to $\mathrm{rSjB} 6$ and SWAP

An ELISA was carried to investigate the immunogenicity of SjB6 as well as the antibody response profile of experimentally challenged mice (susceptible host) and rats

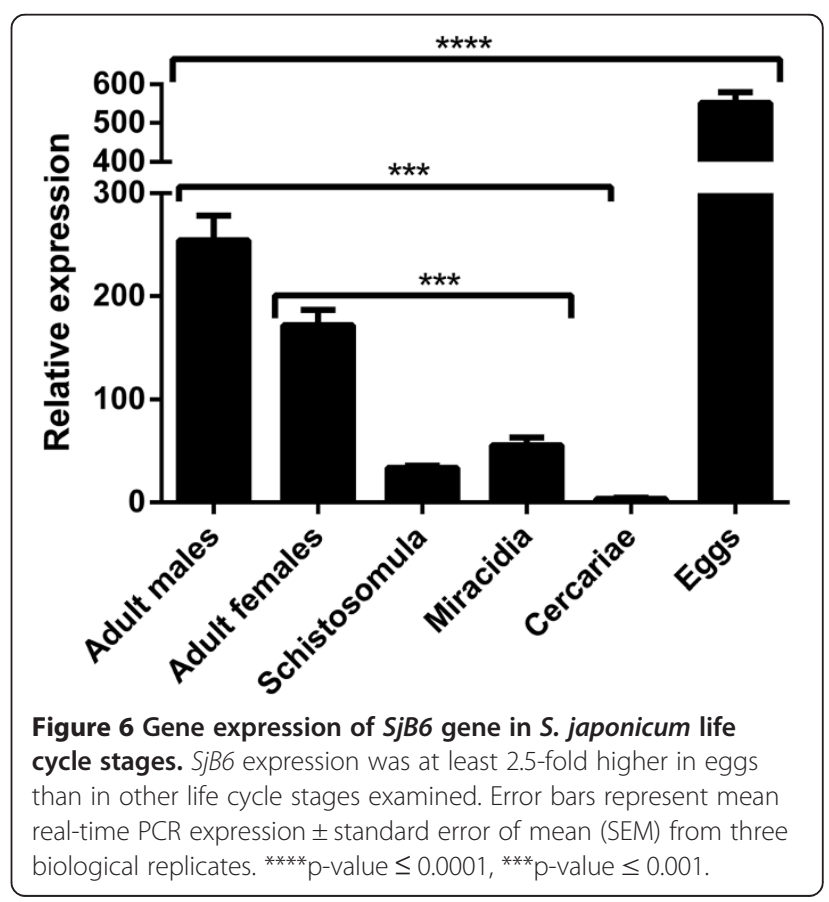




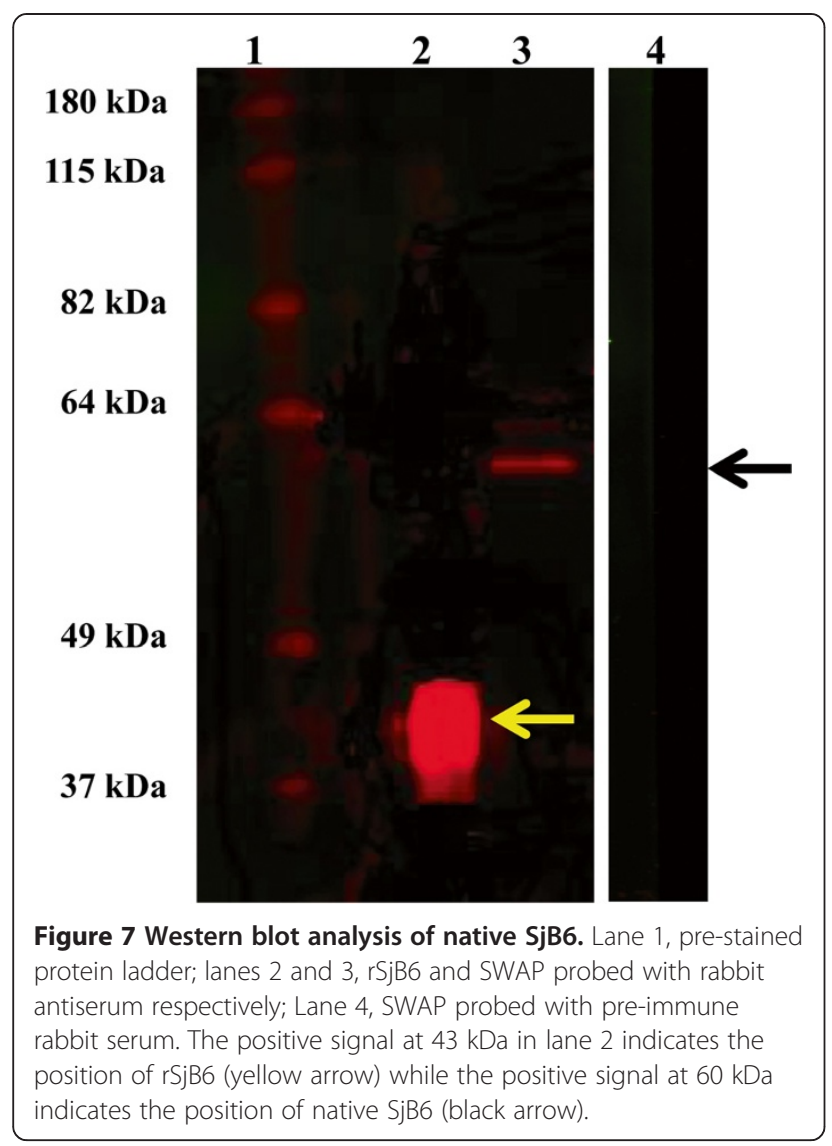

(resistant host) against this serpin. The ELISA results clearly showed strong rat serum antibody reactivity against rSjB6 six weeks post-infection and this response was highly significant $(\mathrm{p}<0.0001)$ when compared with the rat sera obtained prior to challenge (Figure 8). The total IgG antibody titre was even more significantly higher in sera collected 6 weeks after a secondary challenge (Figure 8).
These results were in direct contrast to those observed in experimentally challenged mice in which no antibody response against $\mathrm{rSjB} 6$ was observed six weeks post-infection (Figure 8). There was a consistently strong antibody response against SWAP in both experimentally challenged mice and rats (Figure 8) which effectively served as a positive control.

\section{Discussion}

Although a number of serpins have been identified and characterised from many parasitic helminths [13], knowledge of schistosome serpins is limited. In this study, we describe the identification and some characteristics of a secretory serpin from $S$. japonicum.

Although the SjB6 amino acid sequence shared low overall sequence homology with other known serpins, SjB6 was identified by closer interrogation as a typical member of the serpin superfamily as it contains conserved characteristic serpin features such as the RCL, serpin signature and serpin motif $[1,4,62]$. In addition, the $\mathrm{SjB} 6$ protein is composed of 387 amino acid residues with a predicted molecular weight of $43.7 \mathrm{kDa}$ and a native molecular weight of $60 \mathrm{kDa}$, which is consistent with other members of the serpin superfamily [63]. Sequence analysis demonstrated that $\mathrm{SjB6}$ contains an $\mathrm{N}$-terminal signal peptide with no transmembrane domain, indicative of a secretory serpin. In addition, secondary and tertiary structure prediction analysis showed that SjB6 contains $9 \alpha$-helices and 15 $\beta$-strands, features again consistent with known serpins $[1,4,18,64]$. RCLs of native inhibitory serpins are always exposed and accessible to target proteases [62] and this was reflected in the predicted tertiary structure of SjB6.

The consensus $20 / 21$ residue peptide " $\mathrm{P}_{17}[\mathrm{E}]-\mathrm{P}_{16}[\mathrm{E} / \mathrm{K} /$ $\mathrm{R}]-\mathrm{P}_{15}[\mathrm{G}]-\mathrm{P}_{14}[\mathrm{~T} / \mathrm{S}]-\mathrm{P}_{13}[\mathrm{X}]-\mathrm{P}_{12-9}[\mathrm{AGS}]-\mathrm{P}_{8-1}[\mathrm{X}]-\mathrm{P}_{1}$, - 4," within the RCL of a serpin determines whether it is categorised as inhibitory or non-inhibitory [4,21]. As a general
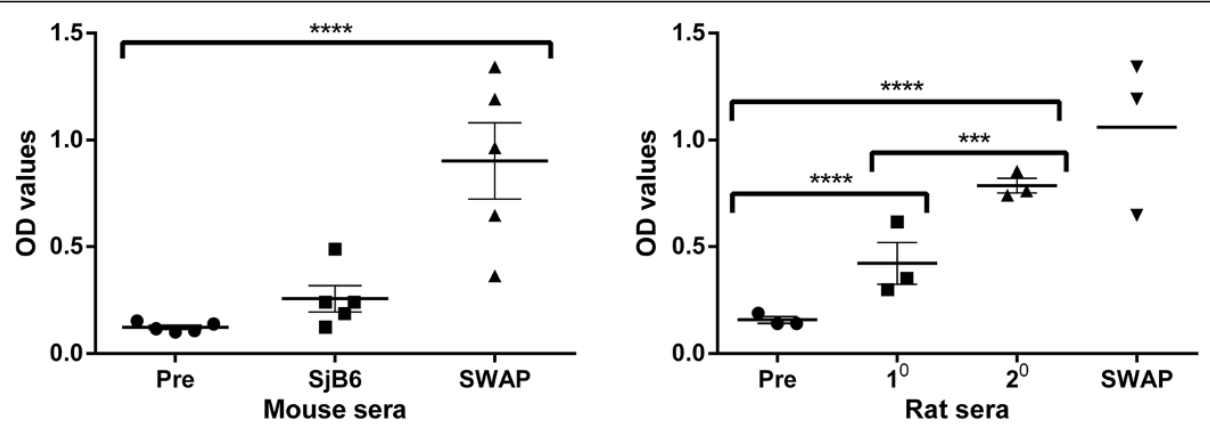

Figure 8 Humoral immune profile of experimentally challenged rodents against rSjB6. Mice $(n=5)$ and rats $(n=3)$ were experimentally challenged with S. japonicum cercariae and immune sera collected six weeks post infection with additional sera collected from the rats 6 weeks post-secondary challenge. Pre-immune sera were also collected prior to the cercarial challenge. Each data point represents an average of 3 replicates. There was no significant difference between the serum antibody levels in the mice before and after challenge (left panel). Rat sera showed high serum reactivity against $\mathrm{rSjB} 6$ after challenge (right panel). Error bars represent mean $+\mathrm{SEM} .1^{\circ}=$ primary challenge, $2^{\circ}=$ secondary challenge, $\mathrm{PRE}=$ pre-immune sera. Statistically significant difference (Two-way ANOVA: ${ }^{* * *}=p$-value $<0.0001,{ }^{* * *}=p$-value 0.0015 ). 
rule, inhibitory serpins contain glycine at position P15, threonine or serine at P14, and positions P12-P9 are occupied by alanine, glycine or serine residues with short-side chains. The corresponding regions of non-inhibitory serpins do not conform to this consensus [4]. These conserved residues of inhibitory serpins are essential for efficient and rapid insertion of the RCL into the " $\mathrm{A}$ " $\beta$-sheet, a process critical to inhibitory activity of a serpin [4]. Furthermore, it is also known that the presence of hydrophobic residues within the hinge region of a serpin provides an advantage for the construction of the skeleton conformation needed for the inhibitory activity of serpins [65]. Further analysis of SjB6 RCL showed that the hinge region is predominantly occupied by hydrophobic amino acid residues which further strengthen the argument that SjB6 is an inhibitory serpin. Multiple structure alignment of the predicted tertiary structure of SjB6 with other known serpins showed that $\mathrm{SjB} 6$ is structurally similar to helminth serpins with highest similarity to a $S$. mansoni serpin (Smpi56) with a root mean squared value of 1.16 . This finding was supported by the result obtained from the phylogenetic analysis of SjB6 sequence and other parasitic helminth serpin sequences which showed that SjB6 clustered very closely with Smpi56.

Rabbit anti-rSjB6 serum detected one band (60 kDa) in native S. japonicum SWAP. The molecular size of the native protein was larger than the recombinantly derived polypeptide $(43 \mathrm{kDa})$ but this was not surprising due to the presence of multiple $\mathrm{N}$-glycosylation sites on the $\mathrm{SjB} 6$ polypeptide indicating that the native $\mathrm{SjB} 6$ undergoes post-translational modifications including glycosylation, as do many other known serpins [18,66]. However, SjB6 was undetected in the adult worm excretory/secretory (E/S) products indicating that $\mathrm{SjB} 6$ is not secreted as part of the E/S products (data not shown). Gene expression profiling of SjB6 gene provided some insight into the possible biological function of SjB6 in S. japonicum. Real-time PCR showed that SjB6 was expressed in the intra-mammalian stages and, especially, in eggs suggesting a possible role for SjB6 in the pathogenesis of schistosomiasis. Schistosomeinduced pathology is a consequence of the host immune response against the parasites' soluble egg antigens [67-69]. Additionally, another possible role for $\mathrm{SjB} 6$ is in protecting the schistosome eggs deposited in the host tissues from attack by host proteases.

Many secreted serpins have been shown to play important roles in host-parasite interactions [70-74]. We used ELISA to determine anti-SjB6 antibody levels (total $\operatorname{IgG}$ ) in the sera of laboratory rodents experimentally infected with $S$. japonicum. The results showed that $\mathrm{rSjB} 6$ was strongly recognised by sera from rats experimentally infected with S. japonicum (Figure 8) suggesting its release into host tissue and induction of a host immune response. Surprisingly, no measurable reactivity against
rSjB6 was detected in the sera of mice experimentally infected with $S$. japonicum. One possible explanation for this observation is the fact that the rat immune system is known to generally recognise more schistosome antigens than the mouse [75] and SjB6 could be one of the molecules not recognised by the murine immune system. Another possibility could be that the amount of $\mathrm{SjB} 6$ released by $S$. japonicum into the host may not be sufficient to induce an immune response by the mouse.

\section{Conclusion}

The full-length cDNA encoding a secretory serpin (SjB6) from S. japonicum was cloned and expressed, and some of its characteristics determined, thereby providing some important insights into the biological functions of this protein. In vitro inhibitory and other biochemical characterisation as well as in vivo studies, gene knock-down experiment transgenesis are required to further our understanding of the biology of SjB6 and its possible roles in the host-parasite interaction.

\section{Competing interests}

The authors declare that they have no competing interest.

\section{Authors' contributions}

AJM, GNG and DPM conceived and designed the study. AJM performed all experiments except the experimental challenge of animals carried out by PD. AJM analysed all experimental data and wrote the entire manuscript. Manuscript was drafted by AJM, GND and DPM. All authors approved the final version of manuscript.

\section{Acknowledgements}

The authors wish to thank Ms Mary Duke (QIMR Berghofer) for performing mouse perfusions and also the Protein Expression Facility (University of Queensland), for assistance with Baculovirus expression systems. We also wish to thank the Histotechnology Department, QIMR Berghofer for their assistance with immunohistochemical analyses. This research was funded by The University of Queensland International Research Tuition Award (UQIRTA) to AJM and NHMRC grants to DPM. DPM is a NHMRC Senior Principal Research Fellow and Senior Scientist at QIMR Berghofer.

Received: 14 May 2014 Accepted: 7 July 2014

Published: 14 July 2014

\section{References}

1. Gettins PG: Serpin structure, mechanism, and function. Chem Rev 2002, 102(12):4751-4804

2. Gettins PG: The F-helix of serpins plays an essential, active role in the proteinase inhibition mechanism. FEBS Lett 2002, 523(1-3):2-6.

3. Gettins PG, Olson ST: Exosite determinants of serpin specificity. J Biol Chem 2009, 284(31):20441-20445.

4. Irving JA, Pike RN, Lesk AM, Whisstock JC: Phylogeny of the serpin superfamily: implications of patterns of amino acid conservation for structure and function. Genome Res 2000, 10(12):1845-1864.

5. O'Donnell RA, Blackman MJ: The role of malaria merozoite proteases in red blood cell invasion. Curr Opin Microbiol 2005, 8(4):422-427.

6. Debrock S, Declerck PJ: Neutralization of plasminogen activator inhibitor-1 inhibitory properties: identification of two different mechanisms. Biochim Biophys Acta 1997, 1337(2):257-266.

7. Sugino M, Imamura S, Mulenga A, Nakajima M, Tsuda A, Ohashi K, Onuma M: A serine proteinase inhibitor (serpin) from ixodid tick Haemaphysalis longicornis; cloning and preliminary assessment of its suitability as a candidate for a tick vaccine. Vaccine 2003, 21(21-22):2844-2851. 
8. Mak P, Enghild JJ, Dubin A: Hamster antithrombin III: purification, characterization and acute phase response. Comp Biochem Physiol B Biochem Mol Biol 1996, 115(1):135-141.

9. Congote LF: Serpin A1 and CD91 as host instruments against HIV-1 infection: are extracellular antiviral peptides acting as intracellular messengers? Virus Res 2007, 125(2):119-134.

10. Thorgersen EB, Ghebremariam YT, Thurman JM, Fung M, Nielsen EW, Holers VM, Kotwal GJ, Mollnes TE: Candidate inhibitors of porcine complement. Mol Immunol 2007, 44(8):1827-1834.

11. Chopin V, Matias I, Stefano GB, Salzet M: Amino acid sequence determination and biological activity of therin, a naturally occuring specific trypsin inhibitor from the leech Theromyzon tessulatum. Eur J Biochem 1998, 254(3):565-570.

12. Fenwick A, Webster JP: Schistosomiasis: challenges for control, treatment and drug resistance. Curr Opin Infect Dis 2006, 19(6):577-582

13. Molehin AJ, Gobert GN, McManus DP: Serine protease inhibitors of parasitic helminths. Parasitology 2012, 139(6):681-695.

14. Gobert GN, Moertel L, Brindley PJ, McManus DP: Developmental gene expression profiles of the human pathogen Schistosoma japonicum. BMC Genomics 2009, 10:128.

15. Consortium, S.j.G.S.a.F.A: The Schistosoma japonicum genome reveals features of host-parasite interplay. Nature 2009, 460(7253):345-351.

16. Rawlings ND, Waller M, Barrett AJ, Bateman A: MEROPS: the database of proteolytic enzymes, their substrates and inhibitors. Nucleic Acids Res 2014, 42(Database issue):D503-D509.

17. Altschul SF, Gish W, Miller W, Myers EW, Lipman DJ: Basic local alignment search tool. J Mol Biol 1990, 215(3):403-410.

18. Huntington JA: Shape-shifting serpins-advantages of a mobile mechanism. Trends Biochem Sci 2006, 31(8):427-435.

19. Han J, Zhang H, Min G, Kemler D, Hashimoto C: A novel Drosophila serpin that inhibits serine proteases. FEBS Lett 2000, 468(2-3):194-198.

20. Miura $Y$, Kawabata S, Wakamiya $Y$, Nakamura $T$, Iwanaga S: A limulus intracellular coagulation inhibitor type 2. Purification, characterization, cDNA cloning, and tissue localization. J Biol Chem 1995, 270(2):558-565.

21. Hopkins PC, Carrell RW, Stone SR: Effects of mutations in the hinge region of serpins. Biochemistry (Mosc) 1993, 32(30):7650-7657.

22. Edgar RC: MUSCLE: a multiple sequence alignment method with reduced time and space complexity. BMC Bioinformatics 2004, 5:113.

23. Edgar RC: MUSCLE: multiple sequence alignment with high accuracy and high throughput. Nucleic Acids Res 2004, 32(5):1792-1797.

24. Tamura K, Peterson D, Peterson N, Stecher G, Nei M, Kumar S: MEGA5: molecular evolutionary genetics analysis using maximum likelihood, evolutionary distance, and maximum parsimony methods. Mol Biol Evol 2011, 28(10):2731-2739.

25. Bjellqvist B, Hughes GJ, Pasquali C, Paquet N, Ravier F, Sanchez JC, Frutiger $S$, Hochstrasser D: The focusing positions of polypeptides in immobilized $\mathrm{pH}$ gradients can be predicted from their amino acid sequences. Electrophoresis 1993, 14(10):1023-1031.

26. Gille C, Frommel C: STRAP: editor for STRuctural Alignments of Proteins. Bioinformatics 2001, 17(4):377-378.

27. Kelley LA, Sternberg MJ: Protein structure prediction on the Web: a case study using the Phyre server. Nat Protoc 2009, 4(3):363-371.

28. Benkert P, Schwede T, Tosatto SC: QMEANclust: estimation of protein model quality by combining a composite scoring function with structural density information. BMC Struct Biol 2009, 9:35.

29. Benkert $P$, Kunzli M, Schwede T: QMEAN server for protein model quality estimation. Nucleic Acids Res 2009, 37(Web Server issue):W510-W514.

30. Guex N, Peitsch MC: SWISS-MODEL and the Swiss-PdbViewer: an environment for comparative protein modeling. Electrophoresis 1997, 18(15):2714-2723.

31. Dereeper A, Guignon V, Blanc G, Audic S, Buffet S, Chevenet F, Dufayard JF Guindon S, Lefort V, Lescot M, Claverie JM, Gascuel O: Phylogeny.fr: robust phylogenetic analysis for the non-specialist. Nucleic Acids Res 2008, 36(Web Server issue):W465-W469.

32. Castresana J: Selection of conserved blocks from multiple alignments for their use in phylogenetic analysis. Mol Biol Evol 2000, 17(4):540-552.

33. Guindon S, Gascuel O: A simple, fast, and accurate algorithm to estimate large phylogenies by maximum likelihood. Syst Biol 2003, 52(5):696-704.

34. Chevenet F, Brun C, Banuls AL, Jacq B, Christen R: TreeDyn: towards dynamic graphics and annotations for analyses of trees. BMC Bioinformatics 2006, 7:439.
35. Dalton JP, Day SR, Drew AC, Brindley PJ: A method for the isolation of schistosome eggs and miracidia free of contaminating host tissues. Parasitology 1997, 115(Pt 1):29-32

36. Chai M, McManus DP, Mclnnes R, Moertel L, Tran M, Loukas A, Jonesa MK, Gobert GN: Transcriptome profiling of lung schistosomula, in vitro cultured schistosomula and adult Schistosoma japonicum. Cell Mol Life Sci 2006, 63(7-8):919-929.

37. Milligan JN, Jolly ER: Cercarial transformation and in vitro cultivation of Schistosoma mansoni schistosomules. J Vis Exp 2011, 54(54):3191.

38. Siracusano A, Rigano R, Ortona E, Profumo E, Margutti $P$, Buttari $B$, Delunardo F, Teggi A: Immunomodulatory mechanisms during Echinococcus granulosus infection. Exp Parasitol 2008, 119(4):483-489.

39. Hitchman RB, Locanto E, Possee RD, King LA: Optimizing the baculovirus expression vector system. Methods 2011, 55(1):52-57.

40. Zhao Y, Chapman DA, Jones IM: Improving baculovirus recombination. Nucleic Acids Res 2003, 31(2):E6-6.

41. Bradford MM: A rapid and sensitive method for the quantitation of microgram quantities of protein utilizing the principle of protein-dye binding. Anal Biochem 1976, 72:248-254.

42. He YX, Salafsky B, Ramaswamy K: Host-parasite relationships of Schistosoma japonicum in mammalian hosts. Trends Parasitol 2001, 17(7):320-324.

43. Jiang W, Hong Y, Peng J, Fu Z, Feng X, Liu J, Shi Y, Lin J: Study on differences in the pathology, $T$ cell subsets and gene expression in susceptible and non-susceptible hosts infected with Schistosoma japonicum. PLoS One 2010, 5(10):e13494.

44. Peng J, Gobert GN, Hong Y, Jiang W, Han H, McManus DP, Wang X, Liu J, Fu Z, Shi Y, Lin J: Apoptosis governs the elimination of Schistosoma japonicum from the non-permissive host Microtus fortis. PLoS One 2011, 6(6):e21109.

45. Knopf PM, Nutman TB, Reasoner JA: Schistosoma mansoni: resistance to reinfection in the rat. Exp Parasitol 1977, 41(1):74-82.

46. Usawattanakul W, Kamijo T, Kojima S: Comparison of recovery of schistosomula of Schistosoma japonicum from lungs of mice and rats. J Parasitol 1982, 68(5):783-790.

47. Carugo O, Pongor S: A normalized root-mean-square distance for comparing protein three-dimensional structures. Protein Sci 2001, 10(7):1470-1473.

48. Bollen A, Herzog A, Cravador A, Herion P, Chuchana P, Vander Straten A, Loriau R, Jacobs P, van Elsen A: Cloning and expression in Escherichia coli of full-length complementary DNA coding for human alpha 1-antitrypsin. DNA 1983, 2(4):255-264.

49. Pak SC, Tsu C, Luke CJ, Askew YS, Silverman GA: The Caenorhabditis elegans muscle specific serpin, SRP-3, neutralizes chymotrypsin-like serine peptidases. Biochemistry (Mosc) 2006, 45(14):4474-4480.

50. Merckelbach A, Ruppel A: Biochemical properties of an intracellular serpin from Echinococcus multilocularis. Mol Biochem Parasitol 2007, 156(1):84-88.

51. Yi D, Xu L, Yan R, Li X: Haemonchus contortus: cloning and characterization of serpin. Exp Parasitol 2010, 125(4):363-370.

52. Hwang JH, Lee WG, Na BK, Lee HW, Cho SH, Kim TS: Identification and characterization of a serine protease inhibitor of Paragonimus westermani. Parasitol Res 2009, 104(3):495-501.

53. Blanton RE, Licate LS, Aman RA: Characterization of a native and recombinant Schistosoma haematobium serine protease inhibitor gene product. Mol Biochem Parasitol 1994, 63(1):1-11.

54. Yan Y, Liu S, Song G, Xu Y, Dissous C: Characterization of a novel vaccine candidate and serine proteinase inhibitor from Schistosoma japonicum (Sj serpin). Vet Parasitol 2005, 131(1-2):53-60.

55. Ghendler $Y$, Arnon $R$, Fishelson Z: Schistosoma mansoni: isolation and characterization of Smpi56, a novel serine protease inhibitor. Exp Parasitol 1994, 78(2):121-131.

56. Modha J, Doenhoff MJ: Schistosoma mansoni host-parasite relationship: interaction of contrapsin with adult worms. Parasitology 1994, 109(Pt 4):487-495.

57. Nagano I, Wu Z, Nakada T, Matsuo A, Takahashi Y: Molecular cloning and characterization of a serine proteinase inhibitor from Trichinella spiralis. Parasitology 2001, 123(Pt 1):77-83.

58. MacLennan K, McLean K, Knox DP: Serpin expression in the parasitic stages of Trichostrongylus vitrinus, an ovine intestinal nematode. Parasitology 2005, 130(Pt 3):349-357.

59. Yenbutr P, Scott AL: Molecular cloning of a serine proteinase inhibitor from Brugia malayi. Infect Immun 1995, 63(5):1745-1753. 
60. Zang X, Atmadja AK, Gray P, Allen JE, Gray CA, Lawrence RA, Yazdanbakhsh M, Maizels RM: The serpin secreted by Brugia malayi microfilariae, Bm-SPN-2, elicits strong, but short-lived, immune responses in mice and humans. J Immunol 2000, 165(9):5161-5169.

61. Anisimova M, Gascuel O: Approximate likelihood-ratio test for branches: A fast, accurate, and powerful alternative. Syst Biol 2006, 55(4):539-552.

62. van Gent D, Sharp P, Morgan K, Kalsheker N: Serpins: structure, function and molecular evolution. Int J Biochem Cell Biol 2003, 35(11):1536-1547.

63. Patston PA: Serpins and other serine protease inhibitors. Immunol Today 2000, 21(7):354.

64. Silverman GA, Bird PI, Carrell RW, Church FC, Coughlin PB, Gettins PG, Irving JA, Lomas DA, Luke CJ, Moyer RW, Pemberton PA, Remold-O'Donnell E, Salvesen GS, Travis J, Whisstock JC: The serpins are an expanding superfamily of structurally similar but functionally diverse proteins. Evolution, mechanism of inhibition, novel functions, and a revised nomenclature. J Biol Chem 2001, 276(36):33293-33296.

65. McCarthy BJ, Worrall DM: Analysis of serpin inhibitory function by mutagenesis of ovalbumin and generation of chimeric ovalbumin/PAl-2 fusion proteins. J Mol Biol 1997, 267(3):561-569.

66. Law RH, Zhang Q, McGowan S, Buckle AM, Silverman GA, Wong W, Rosado CJ, Langendorf CG, Pike RN, Bird PI, Whisstock JC: An overview of the serpin superfamily. Genome Biol 2006, 7(5):216.

67. Hirata M, Kage M, Hara T, Yoneda Y, Zhang M, Fukuma T: Schistosoma japonicum egg granuloma formation in the interleukin-4 or interferon-gamma deficient host. Parasite Immunol 2001, 23(6):271-280.

68. Hoffmann KF, Cheever AW, Wynn TA: IL-10 and the dangers of immune polarization: excessive type 1 and type 2 cytokine responses induce distinct forms of lethal immunopathology in murine schistosomiasis. J Immunol 2000, 164(12):6406-6416.

69. Chuah C, Jones MK, Burke ML, McManus DP, Gobert GN: Cellular and chemokine-mediated regulation in schistosome-induced hepatic pathology. Trends Parasitol 2014, 30(3):141-150.

70. Imamura S, Namangala B, Tajima T, Tembo ME, Yasuda J, Ohashi K, Onuma M: Two serine protease inhibitors (serpins) that induce a bovine protective immune response against Rhipicephalus appendiculatus ticks. Vaccine 2006, 24(13):2230-2237.

71. Leboulle G, Crippa M, Decrem Y, Mejri N, Brossard M, Bollen A, Godfroid E: Characterization of a novel salivary immunosuppressive protein from Ixodes ricinus ticks. J Biol Chem 2002, 277(12):10083-10089.

72. Leboulle G, Rochez C, Louahed J, Ruti B, Brossard M, Bollen A, Godfroid E: Isolation of Ixodes ricinus salivary gland mRNA encoding factors induced during blood feeding. Am J Trop Med Hyg 2002, 66(3):225-233.

73. Mulenga A, Khumthong R, Chalaire KC: Ixodes scapularis tick serine proteinase inhibitor (serpin) gene family; annotation and transcriptional analysis. BMC Genomics 2009, 10:217.

74. Prevot PP, Adam B, Boudjeltia KZ, Brossard M, Lins L, Cauchie P, Brasseur R, Vanhaeverbeek M, Vanhamme L, Godfroid E: Anti-hemostatic effects of a serpin from the saliva of the tick Ixodes ricinus. J Biol Chem 2006, 281(36):26361-26369.

75. Sepulveda J, Tremblay JM, DeGnore JP, Skelly PJ, Shoemaker CB: Schistosoma mansoni host-exposed surface antigens characterized by sera and recombinant antibodies from schistosomiasis-resistant rats. Int J Parasitol 2010, 40(12):1407-1417.

doi:10.1186/1756-3305-7-330

Cite this article as: Molehin et al:: Characterisation of a secretory serine protease inhibitor (SjB6) from Schistosoma japonicum. Parasites \& Vectors 2014 7:330.

\section{Submit your next manuscript to BioMed Central and take full advantage of:}

- Convenient online submission

- Thorough peer review

- No space constraints or color figure charges

- Immediate publication on acceptance

- Inclusion in PubMed, CAS, Scopus and Google Scholar

- Research which is freely available for redistribution 